\title{
Acting locally to mitigate globally: climate action in the Anthropocene
}

\author{
Marcus Carson \\ Published online: 3 February 2015 \\ (C) The Author(s) 2015. This article is published with open access at Springerlink.com
}

\begin{abstract}
The idea that individual- or local-scale actions can combine to have global effects and relevance is of course not limited to the natural sciences. Slogans such as "think globally, act locally" have been used for many years in an effort to encourage individuals and locally anchored movements to see their place - and their actions - as part of a broader effort. What the message embedded in the term Anthropocene highlights, however, is the fact that a multitude of individuals acting locally influences global conditions whether or not we "think" globally. Nowhere is this more true than with climate change. In the Arctic, the consequences of climate change are more visible, yet the links between action and consequences appear more distant, and this illustrates a key challenge. Local action has often been pursued in the shadow of the global negotiations, yet many of the most important breakthroughs currently being made are arguably being accomplished at the local and regional levels. This is in fact the silver lining in that dark cloud surrounding the Anthropocene. It points to the critical importance of local level action on climate change, both from a governance perspective and for improving underlying the socio-technical conditions that influence what is possible in global efforts.
\end{abstract}

Keywords Climate change $\cdot$ Local action $\cdot$ Arctic $\cdot$ Local climate mitigation

M. Carson $(\bowtie)$

Stockholm Environment Institute, Post Box 24218, SE 104

51 Stockholm, Sweden

e-mail: marcus.carson@sei-international.org

URL: http://www.sei-international.org

URL: http://sei-international.org/staff?staffid $=243$

M. Carson

87D Linnégatan, 11523 Stockholm, Sweden
Even as final preparations were feverishly underway for the December 2014 climate negotiations in Lima, Peru, a committee of scientists was meeting in Berlin to consider how one might properly judge whether the planet has entered a new geological epoch (The Guardian 2014). Some 15 years after the designation "Anthropocene" was coined by Paul Crutzen, it has yet to become a household word.

Nevertheless, the "paradigm shift" to which it gives a name is gaining ground. As an insightful 2011 editorial in the Economist quite accurately noted, "the term paradigm shift is bandied around with promiscuous ease. But for the natural sciences to make human activity central to its conception of the world, rather than a distraction, would mark such a shift for real."(Economist 2011). Indeed. Where human populations were previously not large enough for human impacts to reach much beyond a local or regional level, the combined force of sheer numbers and technological magnification of our impact is now recognized to have become a major geophysical force powerfully influencing the physical systems of our planet (Crutzen and Schwägerl 2011).

The idea that individual or local scale actions can combine to have global effects and relevance is of course not limited to the natural sciences. Slogans such as "think globally, act locally" have been used for many years in an effort to encourage individuals and locally anchored social movements to see their place - and their actions - as part of a broader effort. What the message embedded in the term Anthropocene highlights, however, is the fact that a multitude of individuals acting locally influences global conditions whether or not we "think" globally. Nowhere is this more true than with climate change.

The Arctic offers a conspicuous example of this phenomenon. Although changes in physical characteristics such as temperature and ocean acidity are proceeding at roughly twice the pace in the Arctic as the rest of the globe (AMAP 2014a, b), the diverse human activities causing these changes are, by and large, being carried out elsewhere. Some of these changes are 
quite dramatic, with the erosion caused by dwindling sea ice threatening coastal villages with oblivion, melting permafrost leading to the collapse of buildings and roads as their formerly solid foundations melt away, and changing precipitation patterns leaving communities without fresh water. While most human activities that produce greenhouse emissions are geographically separated from their climate-related consequences in the Arctic, they are much more closely linked in time than elsewhere, making the Arctic a sort of planetary early warning system that provides a preview of the scope and speed of climate-related environmental change. Moreover, the Arctic is not merely a bellwether of change. There is a saying that "what happens in the Arctic doesn't stay in the Arctic," as North Americans who have learned about the polar vortex have learned. With the Arctic occupying a central role in our planet's climate system, Arctic changes caused by actions elsewhere may well boomerang back to be felt elsewhere. This reality would seem to argue for a slight modification of the slogan to "think globally, act locally, and keep a really close watch on the Arctic." Yet in the Arctic as elsewhere, many perceive retreating snow and ice more as opportunity than threat - perhaps because many of the opportunities appear even nearer in time than the threats, or perhaps because the effects are directly experienced by a relative few.

A full 5 years after the high hopes and ambitions that converged in Copenhagen around the climate talks, the pace of progress in the United Nations Framework Convention on Climate Change (UNFCCC) negotiations remains at a crawl. Both individually and as blocs, countries have proven reluctant to embrace emissions reductions at anything approaching the level of ambition science indicates will be needed to avoid dangerous warming (Grubb 2011). Even countries such as Sweden, with extremely good preconditions for dramatically reducing emissions (few domestic fossil fuel resources, abundant hydropower and a broad-based political support for climate mitigation), are moving far less decisively than many analysts believe possible — or necessary (Rockström and Eklund 2012).

The core logic of the international talks is that binding commitments agreed to in the UNFCCC process will be implemented at the national and subnational levels. Yet, while the success or failure of negotiations is dependent on the effectiveness of the negotiations themselves, negotiators' instructions are rooted in the very structures that they are expected to change. It is well known that internal social, cultural, and institutional dynamics, in combination with the energyrelated infrastructure of the individual participating countries, create their own powerful path dependencies.

In considering what is possible in any particular round of negotiations, far too little is made of what Sweden's former chief negotiator Bo Kjellén (2009) characterizes to as “enabling conditions." Kjellén's insight echoes Putnam (1988) classic work on "two-level games," which highlighted how policy influence flows in both directions in a multi-level (Hooghe and Marks 2003), multi-scalar (Cash et al. 2006), and highly interactive process that involves policy, behavior, physical infrastructure, and feedbacks. In short, individual countries find it much easier to strike agreements committing them to changes they are already embracing domestically. As new practices become institutionalized at a local and regional level across significant portions of a country's geography, it deprives scare scenarios of their relevance, weakens oncepowerful interests, and strengthens others.

The importance of climate mitigation action across scales has gained increasing recognition over the past decade. Subnational action was especially vital for setting changes in motion in the United States of America (USA) as the Bush administration formally disengaged from the Kyoto Protocol, with some scholars highlighting state-level initiatives (Rabe 2004) and others pointing to the key role of cities in governance and implementation of climate policies (Betsill and Bulkeley 2006). These subnational actors make an essential contribution in driving change toward national-level policy and implementation "tipping points (Carson and Román 2010)." Moreover, the "uneven geographic distribution of obstacle and opportunity" creates "hotspots" where social, political, ideational, and infrastructural factors converge to support sociopolitical innovation and "dead spots" where change efforts are blocked or simply gain no traction (Carson 2011).

Many, if not most of these hotspots of activity, lie where a confluence of social factors and energy infrastructure makes for a comparatively low threshold for change. They are regions that are culturally conducive, in that environmentalist sympathies are strong, where willingness to use regulation as a tool for addressing social problems is not ruled out based on ideological proclivities, and where there are strong organized actors who see opportunity in pursuing a clean energy transition. They are also regions where coal or other fossil energy sources play a relatively minor role in electricity production or in economic well-being. In the USA, this confluence is seen in West Coast states such as California, Washington, and Oregon or the East Coast states that participate in the Regional Greenhouse Gas Initiative (RGGI). In Europe, Sweden offers a good example of this confluence, while Norway and Germany illustrate more complex cases (with Norway having significant revenues from its oil reserves and revenues and Germany having had a significant portion of its electricity produced with coal).

Moreover, the local level is where many of the very practical changes involved in reducing energy consumption and carbon emissions must be implemented (Mulugetta et al. 2011; Walker 2011). Municipalities exert decisive influence over local infrastructure and energy use, structuring public and private behavior for decades to come. As small and mid-sized cities grow, they have a unique opportunity to employ today's climate and energy-related knowledge to set the scene for future city inhabitants and roles as tenants, transport users, and energy consumers. These are the kinds of elements highlighted by David Victor (2011) in his argument for shifting attention to local 
efforts to more effectively combat climate change. One critical point to make is that even comparatively ambitious emissions reduction goals that might be embraced by a given country in the international negotiations must ultimately be converted into concrete change for those reductions to be achieved. Many, if not most of those changes, must be carried out at the local level.

This brings us back to the Anthropocene. The core logic of the term is that humanity now represents a significant geophysical force, due both to our sheer numbers and through the technological magnification of our impacts. In and of itself, it is a neutral concept. In practice, however, it is frequently invoked as part of a dark cloud of dire warning - of the harm we are unintentionally creating, of the risks we are unwittingly magnifying. Since it is the global nature of these harms and risks that makes them so foreboding and serious, many of the efforts to respond have focused at that global level, and much energy and attention has been rightly given to these global efforts. One result, however, is that local action has often been pursued in the shadow of the global negotiations, yet many of the most important breakthroughs currently being made are arguably being accomplished at the local and regional levels (Bulkeley et al. 2011) and through coordination efforts among constellations of local and regional actors, such as the International Council for Local Environmental Initiatives (ICLEI), the C40 Cities Climate Leadership Group (C40), the US Conference of Mayors Climate Protection Program, or the European Union's Covenant of Mayors. This is in fact the silver lining in that dark cloud surrounding the Anthropocene. It points to the critical importance of local level action on climate change, both from a governance perspective and for improving underlying the socio-technical conditions that influence what is possible in global efforts.

Acknowledgments The author would like to acknowledge the Swedish Research Council Formas for research funding that has contributed to this article.

Open Access This article is distributed under the terms of the Creative Commons Attribution License which permits any use, distribution, and reproduction in any medium, provided the original author(s) and the source are credited.

\section{References}

AMAP (2014a) Arctic ocean acidification 2013: an overview. Arctic Monitoring and Assessment Program, Oslo, 2014

AMAP (2014b) Snow, water, ice and permafrost in the arctic (SWIPA): climate change and the cryosphere. Arctic Monitoring and Assessment Program, Oslo, 2014

Betsill MM, Bulkeley H (2006) Cities and the multilevel governance of global climate change. Glob Gov 12:141-159

Bulkeley H, Broto VC, Hodson M, Marvin S (eds) (2011) Cities and low carbon transitions. Routledge, London

Carson M (2011) Paradigm shift in US climate policy, but where is the system shift? In: Pelling M, Redclift M, Navarette DM (eds) Climate crisis and the crisis of capitalism. Rougledge, London

Carson M, Román M (2010) Tipping point: crossroads for US climate policy. In: Lever-Tracy C (ed) Routledge international handbook of climate change and society. Routledge, London

Cash DW, Adger WN, Berkes F, Garden P, Lebel L, Olsson P, Pritchard L, Young O (2006) Scale and cross-scale dynamics: governance and information in a multi-level world. Ecol Soc 11:8-20

Crutzen PJ, Schwägerl C (2011) Living in the Anthropocene: toward a new global ethos. Environ 360, 2012-01-24.

Economist (2011) Welcome to the Anthropocene: geology's new age. In Economist: the economist newspaper limited.

Grubb M (2011) Durban: the darkest hour? Clim Pol 11:1269-1271

Guardian (2014) Anthropocene: Is this the new epoch of humans? In The Guardian news and media limited.

Hooghe L, Marks G (2003) Unraveling the central state: types of multi-level governance. Institute for Advanced Studies, Vienna

Kjellén B (2009) New diplomacy for sustainable development. Taylor and Francis, London

Mulugetta Y, Jackson T, van der Horst D (2011) Carbon reduction at community scale. Energy Policy 38:7541-7545

Putnam R (1988) Diplomacy and domestic politics: the logic of two-level games. Int Organ 42:427-460

Rabe BG (2004) Statehouse and greenhouse: the emerging politics of American climate change policy. Brookings Institution Press, Washington

Rockström J, Eklund K (2012-04-24) Världen har backat från ambitionerna för 40 år sen” DN Debatt.

Victor D (2011) Global warming gridlock: creating more effective strategies for protecting the planet. Cambridge University Press, Cambridge

Walker G (2011) The role for 'community' in carbon governance. WIREs Clim Chang 2. 